\title{
Biografía
}

\section{Dr. Clodomiro Picado Twight (1887-1944)}

Clodomiro Picado Twight jugó un papel central en el desarrollo inicial de varias ramas de la ciencia en Costa Rica. $\mathrm{Su}$ formación académica se inició en el Colegio San Luis Gonzaga, en Cartago, donde recibió el influjo de valiosos naturalistas y educadores costarricenses y extranjeros. Posteriormente se le concedió una beca para efectuar estudios superiores en la Universidad de Paris, los cuales concluyó exitosamente con la presentación de una tesis en la que estudió diversos aspectos de la biología de las bromeliáceas epífitas de Costa Rica. Antes de regresar a nuestro país, se capacitó en el Instituto Pasteur y en el Instituto de Medicina Colonial, también en Francia. En dichoscentros, recibióuna sólida formación en Microbiología, Inmunología y Química Clínica. Su formación, por lo tanto, transitó por una amplia gama de disciplinas científicas.

Al regresar a Costa Rica, en 1913, asumió la dirección del Laboratorio Clínico del Hospital San Juan de Dios, laboratorio que había sido iniciado por el Dr Carlos Durán Cartín. Dr. Clodomiro Picado convirtió dicho laboratorio en un centro moderno de análisis clínicos, introduciendo el diagnóstico de laboratorio, de una manera permanente y consistente, en el medio hospitalario nacional. Su trabajo permitió implementar y adaptar una gran cantidad de métodos microbiológicos, serológicos, hematológicos y de química clínica para el diagnostico de enfermedades. Así, el Dr. Clodomiro Picado fue el pionero de lo que sería la futura profesión de Microbiología y Química Clínica, desarrollada décadas más tarde en la Universidad de Costa Rica.

Por otra parte, el Dr. Picado estudió, desde las perspectivas clínica y experimental, una gran cantidad de enfermedades de nuestro medio. Al estar ubicado en el Hospital San Juan de Dios, contó con valioso material y con la colaboración de destacados médicos y técnicos de dicho centro de salud. Su aporte principal en este ámbito se ubica en lo que podríamos denominar la Medicina Experimental, es decir, el análisis de trastornos diversos desde una perspectiva experimental de laboratorio. Entre muchos temas que motivaron su interés, y en los cuales publicó trabajos de alto nivel científico, se encuentran la fisiopatología tiroidea, las enfermedades infecciosas, el envejecimiento, los envenenamientos por mordeduras de serpiente, el análisis de la calidad sanitaria de las aguas de consumo humano y la búsqueda de nuevas terapias para diferentes dolencias. Su amplia labor científica quedó plasmada en más de 100 publicaciones y libros publicados en Costa Rica y en el exterior. En dichos trabajos se aprecia claramente el alto nivel de su trabajo científico, el diseño meticuloso de los experimentos y su enorme creatividad para generar hipótesis novedosas y para superar los escollos que encontraba en nuestro medio para lograr desarrollar su trabajo.

Sus actividades en el hospital lo llevaron no solo a estudiar diversas patologías y su tratamiento, sino también a proponer soluciones concretas a las mismas. Cabe destacar, en este sentido, su empeño por brindar soluciones al problema de los envenenamientos por mordeduras de serpiente, que constituían un flagelo para la salud de los trabajadores agrícolas. En este tema, además de estudiar las serpientes y sus venenos, se empeñó en establecer una colaboración con el Instituto Butantan, de Brasil, que le permitió traer al país los sueros anfiofídicos brasileños, que eran efectivos contra los venenos de las serpientes de Costa Rica. Estableció un 'banco' de sueros antiofídicos en el Hospital San Juan de Dios e introdujo exitosamente en Costa Rica la seroterapia como tratamiento para esta dolencia. Por otra parte, fomentó la elaboración y aprobación de una "Ley de defensa contra el ofidismo", legislación pionera en América, que permitió enfrentar el problema desde una perspectiva salubrista más amplia.

Más allá de los temas biomédicos, el Dr. Clodomiro Picado también estudió algunas enfermedades de nuestros principales cultivos (café, banano, etc.) y aspectos de fisiología vegetal. Así mismo, su temprano interés en temas estrictamente biológicos continuó a lo largo de su carrera. Ejerció cargos docentes en el Liceo de Costa Rica y en el Colegio Superior de Señoritas, donde impulsó una enseñanza más creativa basada en la experimentación.

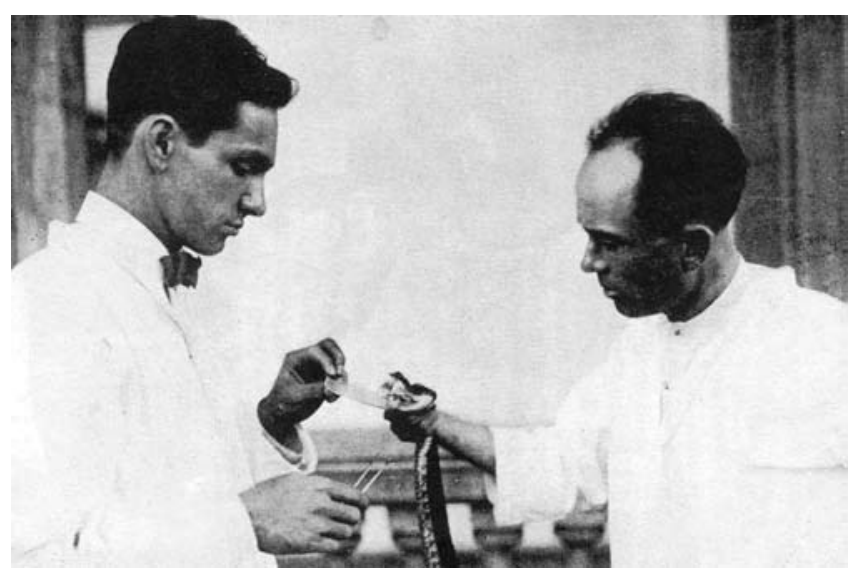

Figura 1. El Dr. Clodomiro Picado Twight (derecha), en el proceso de obtención de veneno de una serpiente Bothrops asper (terciopelo). lo acompaña Luis Bolaños, uno de sus principales colaboradores en el Laboratorio Clínico del Hospital San Juan de Dios." 
Además de su intensa y prolífica actividad científicotecnológica, el Dr. Clodomiro Picado fue un individuo comprometido con el análisis y la búsqueda de soluciones a muchos problemas del país. Frecuentemente intervino en polémicas sobre temas nacionales y mantuvo una actitud crítica ante expresiones poco solidarias y corruptas de ciertos sectores nacionales. Sus ensayos periodísticos, publicados en el volumen VI de sus Obras Completas, dan testimonio de esa responsabilidad social que lo caracterizó.

En suma, la obra del Dr. Clodomiro Picado constituye un punto de referencia fundamental en el desarrollo de la ciencia en Costa Rica y la región. Su creatividad, su capacidad para superar dificultades, su pasión por el conocimiento, su interés por contribuir a resolver problemas nacionales y su responsabilidad social en un sentido amplio son una guía que debemos siempre tener presente para que la ciencia y la tecnología ocupen el lugar que les corresponde en la vida nacional.
José María Gutiérrez
Instituto Clodomiro Picado
Facultad de Microbiología
Universidad de Costa Rica
Correo electrónico: jose.gutierrez@ucr.ac.cr 